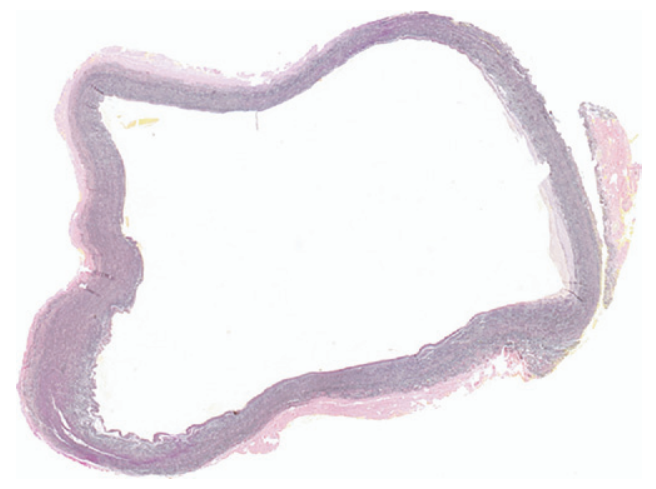

Figure 2. Histologic section taken from an allograft shunt 18 months after implantation, showing no signs of inflammation or rejection.

\section{Discussion}

Carotid artery allografts offer distinct advantages over synthetic grafts, particularly in small infants. Human tissue demonstrates no oozing of blood or serous leakage from the suture holes and is more resistant to infection than are synthetic materials. The lack of thrombogenicity is also a major advantage when using biologic tissue. In this series, all shunts remained patent, even in the graft that narrowed through a suspected immunologic response. In the absence of a local tissue bank, the availability of human carotid arteries is problematic. So far, the potential uses of donated blood vessels are underestimated. For example, we use descending aortic tubes to improve the safety of left ventricular assist device cannulation and ascending aorta or pulmonary artery wall as patch material where eventual stiffening and calcification is unimportant. Accordingly, we obtain as much healthy vascular tissue as possible when harvesting aortic and pulmonary valves from cadaveric donors. The risk of immunoreactivity has not proven to be of importance in the short term between shunting and the corrective procedure. Bogats and colleagues ${ }^{2}$ and Tam and associates ${ }^{3}$ have reported the use of saphenous vein allografts as an alternative for modified Blalock shunts. In their series there was no fibrosis or calcification seen in 4 patients up to 55 months. ${ }^{2}$

In conclusion, the use of carotid allograft facilitates the microvascular anastomoses in infants with cyanotic congenital heart disease. These conduits have a very low propensity for thrombosis, and the potential for immunogenecity does not preclude their use.

\section{References}

1. de Leval MR, McKay R, Jones M, Stark J, Macartney FJ. Modified Blalock-Taussig shunt. Use of subclavian artery orifice as flow regulator in prosthetic systemic-pulmonary artery shunts. $J$ Thorac Cardiovasc Surg. 1981;81:112-9.

2. Bogats G, Kertesz E, Katona M, Toszegi A, Kovacs GS. Modified Blalock-Taussig shunt using allograft saphenous vein: six years' experience. Ann Thorac Surg. 1996;61:58-62.

3. Tam VK, Murphy K, Parks WJ, Raviele AA, Vincent RN, Strieper M, et al. Saphenous vein homograft: a superior conduit for the systemic arterial shunt in the Norwood operation. Ann Thorac Surg. 2001;71:1537-40.

\title{
Unusual systemic venous return with absence of superior caval veins
}

\author{
Phalla Ou, MD, , Giulio Calcagni, MD, ${ }^{\mathrm{b}}$ Davide Marini, MD, Jerome Le Bidois, MD, ${ }^{\mathrm{b}}$ Pietro Gallo, MD, \\ Francis Brunelle, MD, PhD, and Damien Bonnet, MD, PhD, ${ }^{\mathrm{b}}$ Paris, France, and Rome, Italy
}

$\mathrm{T}$ he absence of the right superior vena cava in situs solitus is a rare anomaly. It is usually associated with persistence of the left superior vena cava or other cardiac abnormalities. ${ }^{1}$ We report here an extremely uncommon case of bilateral absence of the superior vena cava, with no

\footnotetext{
From the Departments of Pediatric Radiology a and Pediatric Cardiology, University Rene Descartes-Paris V, Hôpital Necker-Enfants Malades, Paris, France; and the Department of Pathological Anatomy, ${ }^{\mathrm{c}}$ University of Rome La Sapienza, Rome, Italy.

Received for publication Dec 11, 2006; accepted for publication Dec 18, 2006.

Address for reprints: Phalla Ou, MD, Department of Pediatric Radiology, Hôpital Necker-Enfants Malades, 149, rue de Sèvres 75743 Paris Cedex 15, France (E-mail: phalla.ou@nck.ap-hop-paris.fr).

J Thorac Cardiovasc Surg 2007;133:1368-9

$0022-5223 / \$ 32.00$

Copyright $\odot 2007$ by The American Association for Thoracic Surgery doi:10.1016/j.jtcvs.2006.12.020
}

associated cardiac anomaly, evaluated through a high-resolution computed tomography (CT) scan.

\section{Clinical Summary}

A 14-month-old boy was admitted to our department because of a cardiac murmur discovered during a routine pediatric evaluation. On physical examination, a systolic heart murmur of grade $1 / 6$ to $2 / 6$ was found. No chronic heart failure or syndromic dysmorphism had been found. The electrocardiogram showed sinus rhythm and no evidence of atrioventricular arrhythmia. A transthoracic echocardiogram found a situs solitus, levocardia with atrioventricular and ventriculoarterial concordance, normal-sized ventricles, normal intracardiac anatomy, and the inferior vena cava draining normally into the right atrium. No superior caval vein could be seen.

We performed cardiac CT scanning to confirm the presumptive diagnosis: 64-slice CT scan (LightSpeed VCT; General Electric, Milwaukee, Wis), slice thickness $0.625 \mathrm{~mm}$, speed of rotation 0.4 second, pitch $0.9,80 \mathrm{kV}$, milliamperes modulated during the acquisition, and peripheral injection of contrast agent (iohexol 300 

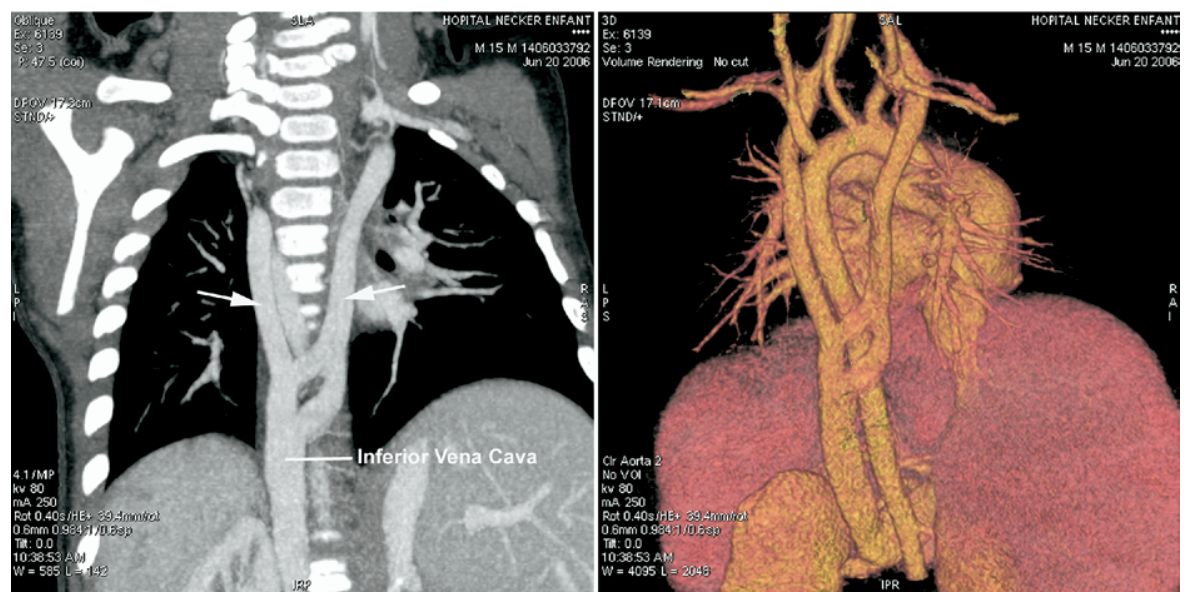

Figure 1. Coronal maximum-intensity projection (left panel) and volumerendered (right panel) computed tomographic images showing the two separate azygos and hemiazygos veins (arrows) that join retrocardially before continuing into the inferior vena cava.

$\mathrm{mgI} / \mathrm{mL}$; volume $1.5 \mathrm{~mL} / \mathrm{kg}$; flow rate of the injection $0.5 \mathrm{~mL} / \mathrm{s}$ ). The acquisition lasted 1.3 seconds and the entire examination lasted approximately 15 minutes.

A very unusual type of systemic venous return was found (Figure 1). Both the right and left jugular and subclavian veins drained into two dorsal veins without communication with the right atrium. Indeed, the two jugular veins continued into azygos and hemiazygos veins, respectively. Then, the latter joined retrocardially above the diaphragm and connected to the inferior vena cava. The hepatic segment of the inferior vena cava was present and terminated normally in the right atrium. No upper caval vein or the equivalent of a bridging innominate vein was seen. The pulmonary veins were normal, draining into the left atrium.

\section{Discussion}

We report here an extremely uncommon case of complete absence of superior caval veins with no associated cardiac defect. Blood from the head, upper limbs, and upper torso drained to the right atrium through both the azygos and hemiazygos veins and the inferior vena cava.

The superior vena cava starts to develop in the fourth week of gestational age from the right common cardinal vein and the right anterior cardinal veins. The right superior vena cava is formed by the confluence of the left and right brachiocephalic veins and drains into the right atrium, while the left part, for a not yet clear mechanism during development, disappears. Absence of the right superior vena cava is a clear pattern, usually associated with persistence of the left superior vena cava and rhythm disorders or other cardiac defect. Bilateral superior vena cava is also a widely known entity; the left one, which usually drains into the right superior vena cava via the innominate vein or directly into the coronary sinus or the inferior vena cava via a cardinal vein, usually persists. ${ }^{1}$

Bilateral absence of the superior vena cava was first reported by Hussain and associates ${ }^{2}$ in a patient with complete atrioventricular block. In the setting of situs solitus, unequivocally lateralized atria, and normal cardiac anatomy, the absence of the superior vena cava is rare. In addition, azygos continuation of the inferior vena cava is commonly associated with absence of the hepatic segment of the inferior vena cava in the setting of left atrial isomerism and is usually unilateral. Cases of the present condition in isolation are rare, especially inasmuch as patients are asymptomatic, with the diagnosis being made only on the basis of radiologic findings. ${ }^{3}$ The condition also can be found incidentally ${ }^{4}$ or can be revealed by a congenital chylothorax, by symptoms of superior vena cava obstruction that appear in the fetus, or by symptoms of an obstructed drainage of the thoracic duct at birth. ${ }^{5}$ In our patient, the upper half of the body drained by azygos and hemiazygos accessory veins that flowed into the inferior vena cava, suggesting a complete involution of the anterior cardinal venous system or lack of development with bilateral persistence of the supracardinal venous system.

Absence of upper caval veins should be considered in the differential diagnosis when a patient presents with radiologic evidence of superior vena cava obstruction, especially if the patient is symptom free with no sign of chronic superior vena cava obstruction. As long as there are doubts about systemic venous drainage, noninvasive $\mathrm{CT}$ or magnetic resonance imaging should be performed as a complement to echocardiography-Doppler and as a substitute for conventional angiography.

\section{References}

1. Buirski G, Jordan SC, Joffe HS, Wilde P. Superior vena caval abnormalities: their occurrence rate, associated cardiac abnormalities and angiographic classification in a paediatric population with congenital heart disease. Clin Radiol. 1986;37:131-8.

2. Hussain SA, Chakravarty S, Chaikhouni A, Smith JR. Congenital absence of superior vena cava: unusual anomaly of superior systemic veins complicating pacemaker placement. Pacing Clin Electrophysiol. 1981;4:328-34.

3. Saunders RN, Richens DR, Morris GK. Bilateral absence of the superior vena cava. Ann Thorac Surg. 2001;71:2041-3.

4. Krasemann T, Kehl G, Vogt J, Asfour B. Unusual systemic venous return with complete absence of the superior caval veins. Pediatr Cardiol. 2003;24:397-9.

5. Lee CY, Jan SL, Wang TM, Chi CS. Congenital chylothorax associated with isolated congenital hypoplastic superior caval vein: a case report. Acta Paediatr. 2005;94:1840-3. 